\section{"Se você pegar locais de maior periferia, esqueça!": a (falta de) atuação pelo direito humano à alimentação adequada na atenção primária à saúde}

\section{"If you're talking about poor communities, forget it!": (lack of) human rights advocacy for adequate food in primary healthcare}

\author{
"Si vas a lugares de mayor marginación, \\ ¡olvídate!": la (falta de) actuación por el derecho \\ humano a una alimentación adecuada en la \\ atención primaria en salud
}

Lúcia Dias da Silva Guerra 1,2,3

Fernanda Cangussu Botelho 1

Ana Maria Cervato-Mancuso 1

\section{Resumo}

Este estudo visou compreender as formas de atuação profissional e as propostas de ações para a efetivação do direito humano à alimentação adequada (DHAA) no contexto da atenção primária à saúde (APS). A partir da abordagem qualitativa, conduzimos entrevistas semiestruturadas (no periodo de maio de 2013 a julho de 2014) com profissionais da saúde que desenvolvem grupos educativos sobre alimentação e nutrição na APS da cidade de São Paulo, Brasil. Realizamos análise de conteúdo buscando identificar as ações propostas em torno da alimentação e tomando como base teórica o DHAA. Identificamos três categorias de atuação profissional a partir das propostas de ações em alimentação e nutrição. A primeira tem a alimentação como dimensão biomédica. A segunda está focada no acesso e disponibilidade de alimentos no território. A terceira tem a realidade alimentar local, dos usuários, centrada na atuação em equipe. Dentre as propostas de ações, havia aquelas para serem realizadas pelos portadores de obrigações do DHAA (profissionais da APS) e aquelas para os próprios titulares do direito executarem (usuários da APS no Sistema Único de Saúde). A alimentação em contextos de pobreza é tratada como um problema sem solução. Este estudo permitiu aproximações entre "o que fazer" e "como atuar" a partir das formas de apropriação da alimentação por meio das concepções, da atuação profissional e das propostas de ações para a efetivação do DHAA na APS. Além disso, possibilitou elucidar a necessidade de compreensão da alimentação como um direito humano e do fortalecimento da responsabilidade dos profissionais da APS como agentes portadores de obrigações do DHAA no contexto das politicas sociais.

Atenção Básica; Direitos Humanos; Segurança Alimentar e Nutricional; Sistema Único de Saúde

\author{
Correspondência \\ L. D. S. Guerra \\ Rua Tenente Azevedo 49, apto. 21, São Paulo, SP \\ 01528-020, Brasil. \\ luciadsguerra@usp.br \\ 1 Faculdade de Saúde Pública, Universidade de São Paulo, São \\ Paulo, Brasil. \\ 2 Centro de Estudos e Pesquisas em Direito Sanitário, São Paulo, \\ Brasil. \\ 3 Centro Universitário Anhanguera, São Paulo, Brasil.
}




\section{Introdução}

Em cenários de periferias, comuns aos grandes centros urbanos, os profissionais da saúde possuem um papel fundamental na construção e na luta para a efetivação dos direitos humanos, por sua responsabilidade técnica e o seu papel como um agente social na identificação das necessidades de saúde da comunidade e na busca de estratégias para enfrentá-las 1. É no âmbito do Sistema Único de Saúde (SUS), no cenário da atenção primária, que os profissionais compõem o corpo técnico de agentes responsáveis pela operacionalização de políticas públicas no seu cotidiano de trabalho, como as de alimentação e nutrição, com destaque para as de segurança alimentar e nutricional 2,3.

A atenção primária à saúde (APS) é o local de atuação do SUS mais próximo da população, o que possibilita uma maior participação social na implementação de políticas públicas, na construção de mudanças e de justiça social com foco na redução da pobreza, na diminuição das desigualdades 4,5 e da fome. No entanto, cabe destacar que a saúde e os serviços de APS no Brasil têm vivenciado o desmonte através do avanço do projeto neoliberal que agudizou sua concretude no âmbito nacional com a Emenda Constitucional no 95/2016 e a atualização/reformulação da Política Nacional da Atenção Primária (PNAB) em 2017. Esse processo provocou um distanciamento conceitual dos princípios da universalidade, integralidade e equidade do SUS, uma valorização a incentivos financeiros fragmentados, a relativização da cobertura, a segmentação do cuidado e a fusão das atribuições dos profissionais da saúde 6 .

Nesse contexto, a alimentação e a saúde tornam-se objetos ainda mais complexos para os profissionais desenvolverem no seu cotidiano 7,8. A necessária articulação entre as políticas sociais de saúde e as de alimentação e nutrição já está bem registrada na literatura científica 2,3, mas quando se trata do direito humano à alimentação adequada (DHAA), permanecem lacunas, especialmente em relação à operacionalização e à efetivação de ações com este referencial teórico 9,10,11.

Acerca da temática da alimentação e nutrição, apesar de estar no cotidiano dos serviços e das ações de saúde da APS, verifica-se que, quando o assunto é este, há na produção científica uma tendência de estudos sobre o nutricionista 12 e das ações centradas na atenção nutricional, promoção da alimentação adequada e saudável, vigilância alimentar e nutricional, prevenção e controle dos agravos nutricionais 13 . O foco no nutricionista como único profissional responsável por essa agenda poderia dar a falsa impressão de que as ações de alimentação e nutrição estão somente sob a realização destes profissionais, no contexto da APS. Não avançando, nesse sentido, para atuação coletiva de todos os profissionais de saúde que compõem a APS, no sentido de trazer à baila os serviços e as ações cotidianas (como visitas domiciliares, reuniões de equipe, grupos educativos, consultas individuais) para o enfrentamento das questões sociais que aniquilam a população brasileira, como a fome e a pobreza, e que impactam diretamente na saúde da população.

Em contraponto, há estudos mostrando que as ações de alimentação e nutrição com foco educativo na APS são realizadas por toda a equipe de saúde 14,15, porém esses estudos sobre educação alimentar e nutricional tendem a focar no "como" se faz e pouco se debruçam em entender "o que" se faz. Ou seja, ainda falta compreender: o que outros profissionais que integram a equipe da APS estão fazendo para o enfrentamento das questões sociais que impactam diretamente a saúde da população; quais ações compõem a sua atuação cotidiana que envolvem a temática da alimentação e nutrição nos territórios de sua responsabilidade.

Entendendo a complexidade de lidar com essa temática, mesmo quando se tem formação específica para este fim 16 , faz-se necessário avançar na compreensão e nas ações da APS envolvendo este tema, para então subsidiar os caminhos de fortalecimento em direção à atuação pelo DHAA, que está entre os direitos sociais a serem efetivados 11 , e o setor de saúde pode ser um cenário para isso. Neste sentido, a educação alimentar e nutricional é um campo de conhecimento e de prática de intervenção multiprofissional muito importante para o DHAA, e a segurança alimentar e nutricional, cujas ações podem e devem envolver nutricionistas e outros profissionais, ou seja, todos os profissionais (da saúde e de outros setores), salientando o seu caráter transdisciplinar de problematização da realidade e promoção da autonomia dos usuários ${ }^{17}$. Trazendo em cena os agentes sociais deste direito ${ }^{10}$, a educação alimentar e nutricional pode ser uma potência para educação política da comunidade, valorização dos espaços de saúde nos serviços e no território, e a prática de cuidado em saúde realizada pelos profissionais, visando a efetivação do DHAA na APS. 
É no sentido de contribuir para o percurso das novas fronteiras que a nutrição pode enunciar para o campo da saúde pública e demarcar as disputas permanentes da alimentação como um direito humano e social que este estudo tem por objetivo compreender as formas de atuação profissional e as propostas de ações para a efetivação do DHAA no contexto da APS.

\section{Percurso metodológico}

Trata-se de um estudo qualitativo realizado no período de maio de 2013 a julho de 2014, com profissionais da saúde que conduzem grupos educativos com a temática da alimentação e nutrição na APS na cidade de São Paulo, Brasil. A construção do universo empírico contemplou diversos cenários de unidades básicas de saúde (UBS) de forma a abranger a diversidade da APS no município e acessar a um grupo variado de profissionais, não restrito a uma única categoria, mas sim à equipe.

Incluímos profissionais da saúde que compõem a equipe da APS, mas os grupos educativos conduzidos por nutricionistas não foram o nosso foco de investigação, por termos o intuito de conhecer "como e o que fazem" outras categorias profissionais que lidam com a temática da alimentação e nutrição, visando a atuação e contribuição destes para realização/efetivação do DHAA. Uma vez que estudos com nutricionista na APS já são bastante realizados e difundidos na literatura científica, buscamos conhecer a diversidade de profissionais da saúde que trabalham em suas ações cotidianas a temática da alimentação e da nutrição. Foram realizadas 26 entrevistas, sendo que cinco delas foram compostas por duplas de profissionais que coordenavam um mesmo grupo educativo, totalizando 31 profissionais entrevistados. As características gerais e de formação dos 31 profissionais que compõem o quadro empírico deste trabalho se encontram descritas no Quadro 1, no qual é possível verificar que a maioria dos profissionais entrevistados é do sexo feminino e com idade entre 30 e 39 anos. Destacam-se os profissionais de enfermagem, medicina e fonoaudiologia. A formação especializada dos profissionais concentrou-se nas áreas de saúde coletiva/saúde pública e saúde da família. A maior parte dos entrevistados atua há menos de cinco anos na unidade, sendo que cinco deles estão na função por tempo inferior a um ano.

O convite para participar do estudo foi feito às cinco Coordenadorias Regionais de Saúde do município, que transmitiram às respectivas UBS. A adesão inicial das supervisões e gerências de saúde ocorreu principalmente pelas regiões mais periféricas da cidade de São Paulo (Leste, Sul e Norte). Por considerarmos necessário contemplar as regiões Centro e Oeste, seguimos com uma segunda onda de convites aos gestores e profissionais de saúde para a participação na pesquisa. Assim, foram visitadas 25 UBS com localizações geográficas diversas. Apesar de terem suas particularidades, o cenário de assistência era muito semelhante em relação à equipe de saúde, o tipo de atividades desenvolvidas, a conformação gerencial do modelo jurídico de gestão público-privada, com parceria entre a Secretaria Municipal de Saúde de São Paulo (SMS/SP) e Organizações Sociais de Saúde (OSS). A distribuição geográfica das UBS era ampla. No entanto, prevaleceu a população periférica, que vive em condições que caracterizam pobreza e outras vulnerabilidades.

A produção dos dados foi por meio de entrevistas semiestruturadas. Para isso, utilizou-se um roteiro composto por uma situação problema abordando uma casuística do cotidiano dos profissionais de saúde da APS, apresentada dentro de um contexto de grupo educativo, que o indagava sobre "como o profissional agiria" diante da dificuldade de acesso e disponibilidade (física e econômica) aos alimentos, visando o enfrentamento da obesidade (uma situação ligada à saúde e alimentação). $\mathrm{O}$ material empírico foi composto por 26 entrevistas, gravadas e transcritas, realizadas com 31 profissionais.

$\mathrm{Na}$ análise dos dados adotou-se uma postura epistemológica analítica e de construção do sentido, entendido como sentido social. Deste modo, a análise de conteúdo guiou a procura de interpretação da relação entre o sentido subjetivo da ação, o ato objetivo (as práticas sociais) e o contexto social em que acontecem as práticas em análise 18,19 .

Foi utilizado o software N-Vivo, versão 10.0 (https://www.qsrinternational.com/nvivo/home), para auxiliar no agrupamento do material empírico em categorias. Para a codificação adotou-se uma marcação característica de investigação indutiva, empregada por uma análise interpretativa das trans- 
Quadro 1

Características dos profissionais da saúde $(n=31)$ que desenvolvem grupos educativos sobre alimentação e nutrição na atenção primária à saúde (APS), nas 25 unidades básicas de saúde (UBS) visitadas nas cinco regiões do Município de São Paulo, Brasil, 2013-2014.

\begin{tabular}{|c|c|c|c|}
\hline CARACTERÍSTICAS & CATEGORIAS & SUBCATEGORIAS & $\mathbf{n}$ \\
\hline \multirow[t]{6}{*}{ Identificação } & \multirow[t]{4}{*}{ Idade * } & $20-29$ anos & 4 \\
\hline & & 30-39 anos & 16 \\
\hline & & 40-49 anos & 3 \\
\hline & & 50-59 anos & 7 \\
\hline & \multirow[t]{2}{*}{ Sexo } & Feminino & 29 \\
\hline & & Masculino & 2 \\
\hline \multirow[t]{13}{*}{ Função, segundo escolaridade } & \multirow[t]{2}{*}{ Ensino Médio } & Agente de promoção ambiental & 2 \\
\hline & & Agente comunitário de saúde & 1 \\
\hline & \multirow[t]{2}{*}{ Técnico } & Auxiliar de enfermagem & 2 \\
\hline & & Técnico em saúde bucal & 1 \\
\hline & \multirow{9}{*}{$\begin{array}{l}\text { Graduado com pós- } \\
\text {-graduação }\end{array}$} & Enfermeiro & 13 \\
\hline & & Médico & 3 \\
\hline & & Fonoaudiólogo & 3 \\
\hline & & Fisioterapeuta & 1 \\
\hline & & Terapeuta ocupacional & 1 \\
\hline & & Assistente social & 1 \\
\hline & & Educador físico & 1 \\
\hline & & Educador em saúde pública & 1 \\
\hline & & Contador & 1 \\
\hline \multirow[t]{18}{*}{ 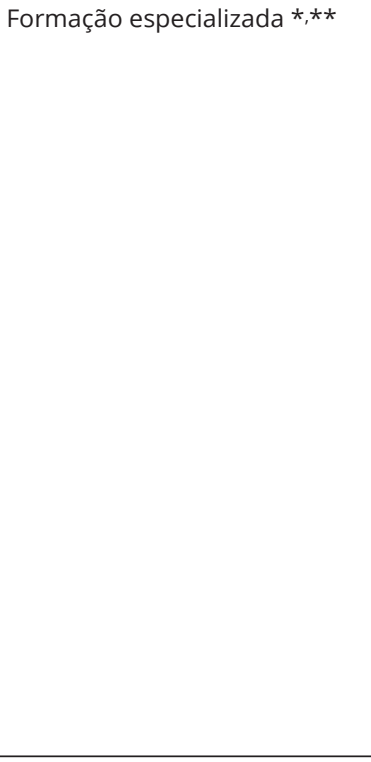 } & \multirow[t]{17}{*}{ Lato sensu } & Saúde coletiva/Saúde pública & 7 \\
\hline & & Saúde da família & 7 \\
\hline & & Educação em saúde & 3 \\
\hline & & Docência & 3 \\
\hline & & Docência em enfermagem & 2 \\
\hline & & Saúde da mulher & 2 \\
\hline & & Enfermagem e obstetrícia & 2 \\
\hline & & Enfermagem em saúde pública & 1 \\
\hline & & Saúde ambiental & 1 \\
\hline & & Saúde funcional em terapia ocupacional & 1 \\
\hline & & Pesquisa clínica & 1 \\
\hline & & Afagia e disfagia em gerontologia & 1 \\
\hline & & Disfagia & 1 \\
\hline & & Administração hospitalar & 1 \\
\hline & & UTI & 1 \\
\hline & & Uroginecologia & 1 \\
\hline & & Urologia & 1 \\
\hline & Stricto sensu (mestrado) & Saúde coletiva & 1 \\
\hline \multirow[t]{5}{*}{ Tempo de trabalho na UBS * } & & $<1$ ano & 5 \\
\hline & & $1-5$ anos & 15 \\
\hline & & $6-10$ anos & 3 \\
\hline & & 11-20 anos & 3 \\
\hline & & 21-30 anos & 4 \\
\hline
\end{tabular}

* Um profissional não informou $(n=30)$. Total de entrevistados: 31 profissionais;

** Há profissionais que tinham mais de uma especialização. 
crições, na qual os códigos têm função referencial e são sinalizadores para certas passagens de texto que informam sobre o fenômeno 18,19 .

$\mathrm{O}$ arcabouço teórico que sustentou a interpretação dos dados empíricos foi composto pelos conceitos de DHAA e de segurança alimentar e nutricional e pelo entendimento da APS como local capaz de contribuir para a realização/efetivação deste direito, com destaque para a potencialidade da educação alimentar e nutricional. Para tanto, utilizou-se o Comentário Geral no 12: O Direito Humano à Alimentação, do Comitê de Direitos Econômicos, Sociais e Culturais da Organização das Nações Unidas (ONU) 20, as diretrizes voluntárias da Organização das Nações Unidas para a Alimentação e a Agricultura (FAO) 21 em apoio à realização progressiva do direito à alimentação no contexto da segurança alimentar e nutricional, em que aparecem as obrigações dos Estados com o DHAA de todos, e a Lei Orgânica de Segurança Alimentar e Nutricional (LOSAN) 22. No que concerne à educação alimentar e nutricional enquanto estratégia que integra aspectos do DHAA, utilizamos o Marco de Referência de Educação Alimentar e Nutricional para as Políticas Públicas 17.

Foi através de uma mescla destes marcos conceituais orientadores da atuação profissional e das ações para a efetivação do DHAA na APS que as categorias de análise e interpretativas foram construídas. As categorias de atuação profissional, assim como o grau de responsabilização dos titulares de obrigações (os profissionais da saúde) e o envolvimento dos titulares do direito (os usuários do SUS na APS), emergiram a partir das propostas de ações.

A pesquisa foi aprovada pelos Comitês de Ética da Faculdade de Saúde Pública da Universidade de São Paulo (USP) e da SMS/SP (parecer no 22/2013).

\section{Resultados e discussão}

As ações propostas pelos entrevistados, categorizadas segundo o grau de responsabilização com a efetivação do DHAA 20,21,22, possibilitaram construir formas de atuação profissional imbricadas às suas concepções de alimentação. Verificam-se, na Figura 1, as três categorias que emergiram a partir do material empírico analisado: atuação voltada para a dimensão biomédica da alimentação; atuação voltada para o acesso e disponibilidade de alimentos no território; e atuação em equipe voltada para a realidade alimentar local dos usuários. É possível identificar, nessa figura, que há envolvimento dos portadores de obrigações (os profissionais da saúde) e dos titulares de direito nas três categorias de atuação (os usuários do SUS na APS), porém com graus de responsabilização diferentes.

\section{Atuação voltada para a dimensão biomédica da alimentação}

As ações sugeridas pelos profissionais sinalizam uma atuação que, além de não reconhecer nenhuma das dimensões do DHAA 20,21,22 (menor grau de responsabilização com a efetivação do DHAA), prioriza o aspecto biomédico ao tratar da alimentação enquanto prática cotidiana do serviço. Nesta categoria, a alimentação é apresentada dentro de contextos de pobreza que, por sua vez, é vista como problema sem solução numa ótica fatalista:

"Não adianta você fazer uma coisa que a realidade não comporta pra eles. Se você pegar locais de maior periferia, esqueça! Esqueça. Não vai ter dinheiro pra comprar" (E12; médica).

Embora a alimentação formalmente faça parte dos direitos sociais dos brasileiros, incorporada pela Emenda Constitucional no 64/2010 23, no presente estudo este reconhecimento não embasa as concepções, as formas de atuação e ações propostas pelos profissionais. Neste sentido, os profissionais parecem aceitar as desigualdades existentes resultando numa atuação despolitizada. Destaca-se que este material empírico foi produzido em um contexto em que as pautas do DHAA e da segurança alimentar e nutricional tinham permeabilidade no debate público e compunham as políticas de governo 2,17,22,24. Ainda assim, a noção de alimentação adequada enquanto direito humano não adentrou o cotidiano do profissional da saúde. No contexto da história recente, em que predominam ataques aos direitos humanos, supressão de instrumentos de participação social e avanços no projeto neoliberal 25 , que tem o Estado como meio para sua reprodução e desmontes dos direitos sociais dos trabalhadores 26, é esperado que o tom das práticas envolvendo a alimentação esteja ainda mais distante da segurança alimentar e nutricional e da defesa dos seus princípios norteadores: o DHAA e a soberania alimentar. 
Figura 1

Ações de alimentação e nutrição propostas para a efetivação do direito humano à alimentação adequada (DHAA) na atenção primária à saúde (APS), segundo categorias de atuação profissional, o grau de responsabilização dos profissionais da saúde e o envolvimento dos usuários do Sistema Único de Saúde (SUS) na APS.

\begin{tabular}{|c|c|c|c|}
\hline & $\begin{array}{l}\text { Menor grau de } \\
\text { responsabilização com } \\
\text { a efetivação do DHAA }\end{array}$ & & $\begin{array}{l}\text { Maior grau de } \\
\text { responsabilização com } \\
\text { a efetivação do DHAA }\end{array}$ \\
\hline \multirow{8}{*}{$\begin{array}{c}\text { Aç̃̃es para o } \\
\text { titular do direito } \\
\text { executar } \\
\text { (usuário do sUS } \\
\text { na APS) }\end{array}$} & \multirow[t]{2}{*}{$\begin{array}{c}\text { Atuação voltada para a } \\
\text { dimensão biomédica da } \\
\text { alimentação }\end{array}$} & $\begin{array}{l}\text { Atuação voltada para o } \\
\text { acesso e disponibilidade de } \\
\text { alimentos }\end{array}$ & \multirow[t]{4}{*}{$\begin{array}{l}\text { Atuação em equipe voltada } \\
\text { para a realidade alimentar } \\
\text { local dos usuários }\end{array}$} \\
\hline & & Adquirir alimentos baratos & \\
\hline & $\begin{array}{l}\text { Preparar de forma mais } \\
\text { saudável }\end{array}$ & Adquirir alimentos da época & \\
\hline & Organizar o dia a dia & Compartilhar receitas & \\
\hline & Associar atividade física & Fazer horta & Trabalhar iunto com o usuário \\
\hline & $\begin{array}{l}\text { Diminuir quantidade/restringir } \\
\text { consumo de alimentos }\end{array}$ & $\begin{array}{l}\text { Adquirir alimentos em feiras/ } \\
\text { sacolões/zona cerealista }\end{array}$ & \\
\hline & Fazer substituições & & \\
\hline & Modificar o paladar & $\begin{array}{l}\text { Aproveltar integralmente } \\
\text { os alimentos }\end{array}$ & \\
\hline & & & $\begin{array}{l}\text { Conhecer as condições de } \\
\text { vida/realidade do território }\end{array}$ \\
\hline & & & $\begin{array}{l}\text { Adaptar orientações para } \\
\text { a realidade local }\end{array}$ \\
\hline & & & $\begin{array}{l}\text { Conhecer os hábitos } \\
\text { dos usuários }\end{array}$ \\
\hline $\begin{array}{l}\text { Ações para o } \\
\text { portador de }\end{array}$ & & & Agir com mais proximidade \\
\hline $\begin{array}{l}\text { obrigaçōes } \\
\text { executar }\end{array}$ & & & Ter empatia \\
\hline $\begin{array}{l}\text { (profissional de } \\
\text { saúde da APS) }\end{array}$ & & & Trabalhar com a equipe \\
\hline & & & Motivar usuários e equipe \\
\hline & & & Planejar o grupo \\
\hline & & & Ensinar a preparar alimentos \\
\hline & & & $\begin{array}{l}\text { Realizar oficinas sobre } \\
\text { aproveitamento integral } \\
\text { dos alimentos }\end{array}$ \\
\hline & Incentivar outras atividades & $\begin{array}{c}\text { Buscar apoio do } \\
\text { nutricionista/NASF para que } \\
\text { este trabalhe preço, }\end{array}$ & $\begin{array}{l}\text { Apresentar exemplos de } \\
\text { alimentação saudável }\end{array}$ \\
\hline & $\begin{array}{l}\text { Não interferir na atuação } \\
\text { de outro profissional }\end{array}$ & disponibilidade dos alimentos & $\begin{array}{l}\text { Abordar a questão } \\
\text { alimentar individualmente }\end{array}$ \\
\hline & Prescrever comida barata & Buscar parcerias para o & Buscar auxílio de revistas de \\
\hline & Pedir exames & dos alimentos & nutricionais \\
\hline
\end{tabular}


Uma vez identificada a impossibilidade de realizar uma alimentação adequada, principalmente em cenários de periferia em que se agudizam as situações de pobreza, os profissionais indicam para os usuários do SUS na APS ações fundamentadas em outros campos disciplinares, como a educação física. Ainda atrelada à noção de balanço energético, lembrando que a situação problema apresentada tratava de casos de obesidade, há orientações como a de reduzir o consumo dos alimentos que aqueles usuários conseguem acessar. Bosi 27 elucida que essa percepção sobre a alimentação, restrita à sua dimensão biológica, advém da construção da ciência da nutrição no Brasil e sua difusão. Para a autora, o campo se desenvolveu tentando sanar a problemática nutricional na sociedade brasileira passando por cima da historicidade do problema.

A discussão inaugurada por Josué de Castro, em 1940, sobre as situações de fome, traz em sua essência a disputa política, econômica e social que é travada permanentemente entre a classe trabalhadora e o sistema capitalista 28 , para a garantia e efetivação dos direitos sociais. No entanto, essa discussão ainda faz parte timidamente do repertório dos profissionais da APS. Estes, por sua vez, se fixam ao tradicional paradigma biomédico, característico das profissões da área da saúde ${ }^{29}$, para responder aos problemas alimentares tão complexos. Estudos apontam que a pobreza e condições de renda são focos temáticos para a compreensão da alimentação como um direito humano e, além disso, podem ser elementos para diferentes estratégias de ação em segurança alimentar e nutricional 30.

Em adição, as ações propostas por esta categoria estão pautadas numa interpretação reducionista da alimentação (Figura 1). A obesidade e a dificuldade financeira para aquisição de alimentos são vistas como incompatíveis. Os profissionais indicam em suas ações, que as suas orientações e prescrições dietéticas são capazes de solucionar o problema alimentar daquele grupo. Assim, a racionalidade biomédica 31 provê elementos suficientes para a resolução de situações que indicam violação do DHAA na população, como exemplifica o seguinte trecho:

"Bom, tem lá um monte de gente obesa que não pode comprar o medicamento, a comida cara. Você dá comida barata. Como é que a comida, como é que couve pode ser cara? Couve, brócolis, catalonha. Um alfacinho. Tá entendendo? Não pode ser cara. Eu acho que todo mundo aqui em São Paulo tem condições. E os que não têm condições de comprar comida com certeza não são obesos. São bem magros e anêmicos e raquíticos. Tem gente aqui no bairro assim. Que não pode comprar comida e é magrinho. O que é gordo ele pode comprar comida. Porque come bastante" (E6; médico).

Dentro da concepção de alimentação pautada no balanço energético, na naturalização de similitude entre medicamento e alimento, a obesidade não é compreendida como uma resultante possível da insegurança alimentar e nutricional. Destacando um desconhecimento da multidimensionalidade que a concepção de alimentação é capaz de trazer, como a concepção de fome oculta (quantitativa e qualitativa), caracterizada pela manifestação de sinais clínicos provenientes da deficiência ou inadequação quantitativa (energia) ou qualitativa (de nutrientes) da dieta, ou ainda das más condições higiênicas e de doenças que comprometem o aproveitamento biológico dos alimentos ingeridos. Este tipo de fome é parcial e vem disfarçado, age sorrateiramente, sem que as pessoas percebam seus malefícios 28 .

A ideia da dificuldade para acessar os alimentos está atrelada a um estereótipo da desnutrição característico dos anos 198032 e dos programas de alimentação e nutrição construídos ao longo da história política do Brasil 33. Nessa categoria de atuação, não foram incorporados os desafios postos à APS pela transição nutricional 13,32 e a complexidade do modo de produção de alimentos pela indústria e, consequentemente, a qualidade do que se come na atualidade 34.

\section{Atuação voltada para o acesso e disponibilidade de alimentos no território}

Nesta categoria, há o reconhecimento da complexidade do acesso e da disponibilidade (física e econômica) de alimentos no território. As ações propostas incluem estratégias como adquirir alimentos no final das feiras livres ou de ações de aproveitamento integral dos alimentos (Figura 1). Considerando que as dimensões do acesso e disponibilidade de alimentos foram incorporadas ao debate da segurança alimentar e nutricional há décadas 35,36, é coerente a existência de uma categoria de atuação profissional com este foco. No entanto, é necessário reconhecer que a busca pela implementação do DHAA por meio de políticas sociais já é conduzida pelo menos há 15 anos pela FAO, assim, avançar para uma concepção mais crítica sobre o que vem a ser a disponibilidade e o acesso físico dos alimen- 
tos neste contexto contemporâneo é fundamental, pois estes são determinados pela maneira como são cultivados, processados, comercializados 37 e consumidos.

Nesta categoria, o profissional da saúde, enquanto um agente do Estado (portador de obrigações), não está envolvido em nenhuma das ações, que são sempre destinadas para outros agentes executarem (o usuário da APS no SUS, outros profissionais que compõe a equipe e outros parceiros institucionais). No Comentário no 12 da ONU 20 fica claro que mecanismos institucionais apropriados deveriam ser estruturados para assegurar um processo representativo para a formulação de uma estratégia, aproveitando-se toda a capacidade técnica nacional relevante para a alimentação e nutrição. Isso evidencia uma posição problemática, já que, no âmbito do SUS, os diferentes profissionais da APS são responsáveis pela operacionalização de diversas políticas públicas no seu cotidiano de trabalho, incluindo-se a de alimentação e nutrição ${ }^{38}$. Essa posição exige dos profissionais da saúde a construção de uma cultura organizacional de valorização do equilíbrio dinâmico entre os saberes dos campos disciplinares e da população, além de uma postura técnica, ética, social, administrativa e política mais crítica mediante suas práticas 38,39 .

Nesta categoria de atuação, percebe-se um profissional impotente diante das questões alimentares, identificando o especialista da área de nutrição como o único capacitado para dar respostas às situações de violação do DHAA, conforme exemplificado no trecho a seguir:

"A gente não tem conhecimento, não somos formadas em Nutrição pra abrir mais o leque. Um pouquinho, a gente consegue abrir, dar outras alternativas. Mas, é, abraçar, não consegue. E aí, ver que a pessoa não tá seguindo aquilo que você orientou porque não tem condições mesmo, financeiras, eu acho difícil. Você vai fazer o quê? Eu não vejo... É poder contribuir com o quê??" (E16; educadora em saúde pública).

Mediante essa impotência apresentada pelo profissional da APS, cabe lembrar que nem sempre os nutricionistas têm produzido propostas tão diferentes dos demais profissionais para abordagem dessa temática nos serviços de saúde ${ }^{9}$. Diante deste sentimento de impotência, as ações que compõem esta categoria estão concentradas no escopo de execução dos usuários do SUS na APS, centrando-se na dimensão individual de responsabilização para a efetivação do DHAA (somente dos titulares do direito) (Figura 1). Ou seja, essa categoria de atuação profissional manifesta uma concepção de APS pouco envolvida com a resolução dos problemas sociais, como a alimentação da população, o que vai na contramão de seu potencial de fortalecimento de promover o DHAA ${ }^{11}$.

A APS, que tem como finalidade ser coordenadora do cuidado e ordenadora da rede, atuando nas necessidades de saúde da população, pautada em princípios como a responsabilização ${ }^{4}$, não aparece nesta categoria. Ao contrário, ficam explícitos os desafios postos para a interface entre a saúde e a alimentação enquanto direitos sociais, como as dificuldades políticas, institucionais e operacionais para concretização das políticas públicas que visam à garantia da segurança alimentar e nutricional para a efetivação do DHAA 2.

Mais uma vez, o contexto socioeconômico é visto como algo sem solução. Há, no trecho de fala, a aceitação de alimentos de menor qualidade. A intermitência do acesso é vista como algo melhor do que nada, havendo uma naturalização da violação do DHAA na situação de pobreza e uma noção de alimentação muito distantes dos princípios do DHAA. As desigualdades econômicas e sociais fundantes do modo de produção contemporâneo são incorporadas nas ações dos profissionais, desvirtuando a lógica da saúde e dos cuidados inerentes à atenção primária 7. Nesse sentido, as ações sugeridas ficam na superficialidade e no âmbito pontual de atuação no problema, uma vez que não contemplam as noções de regularidade e permanência de promover o DHAA, assim como a perspectiva das obrigações do Estado de respeitar, proteger, promover e de prover esse direito 20:

“...Então, a feira, no finalzinho da feira, todo mundo sabe que é mais em conta. Então, ó, vai na feira, né, mais tarde, você consegue comprar mais por menos, né? É... Talvez, a qualidade não deve ser lá grande coisa, mas... Melhor do que... Melhor, né? Você comer durante um, dois dias, é melhor do que não comer nada" (E16; educadora em saúde pública).

\section{Atuação em equipe voltada para a realidade alimentar local dos usuários}

Nesta categoria, as ações propostas têm como base a relação interpessoal e a responsabilidade coletiva, ou seja, envolvem diversos agentes para a realização de ações no sentido da efetivação do DHAA (Figura 1). Isso está compatível com o trabalho na APS, que sugere ações em equipe, dinamicidade 
entre as pessoas e conexão com o território, com o modo de vida das populações, com o emprego de tecnologias leves, não menos complexas, mas que buscam resolver os problemas de saúde 40 a partir das necessidades de saúde da população ${ }^{6}$. Ainda que esta forma de atuação concentre ações para os profissionais de saúde executarem, ela envolve também os usuários do SUS na APS, como parte deste processo de realização (Figura 1). Mas, esta ação não parece envolver o usuário como agente do processo, ao contrário, parece ainda estar situada sob a perspectiva da tutela do Estado e seus agentes, não avançando para uma participação social fundamentada.

A noção do cuidado em saúde transcende o âmbito da orientação e da prescrição dietética, centrando-se efetivamente na atenção nutricional com a tentativa de resolução do problema. $\mathrm{O}$ alicerce das ações coletivas está no encontro com a realidade concreta dos usuários, manifestada na empatia, no trabalhar junto e agir com maior proximidade. Concomitantemente, existem ações da esfera prática, como ensinar a preparar alimentos e realizar oficinas culinárias que podem construir uma sociabilidade capaz de transformar a realidade social vivenciada de fome e pobreza. Langdon 41 destaca que dar ênfase na perspectiva dos agentes sociais na vida concreta e em sua capacidade de ação possibilita conhecer como são construídos o conhecimento e as práticas locais de saúde e isso fornece subsídios fundamentais para a constituição das políticas públicas. De forma geral, pelo conteúdo das ações sugeridas, o maior grau de responsabilização com a efetivação do DHAA está expresso nesta forma de atuação (Figura 1), ainda que a noção de direito humano não apareça explicitamente. É nesta forma de atuação que se observou a dialogicidade entre profissional e usuário, alimentação e educação, essencial para a educação alimentar e nutricional.

Há um ideal de alimentação adequada. No entanto, o cenário de pobreza obstaculiza a sua concretização, ficando ao encargo do profissional a criatividade de buscar alternativas alimentares viáveis para a população. Por sua vez, o profissional da APS não se vê como agente de transformação no nível local, aspecto importante quando se atua na perspectiva dos direitos humanos 42, buscando problematizar o papel do Estado (e seus agentes) e dos usuários para a construção das garantias de uma alimentação adequada para todos. Nesta categoria, cabe ao profissional de saúde a adaptação de suas ações diante dos constrangimentos contextuais, conforme o seguinte trecho:

"Não adianta também eu sonhar muito alto, eu quero que todo mundo coma coisa orgânica, natural, porque não é essa a realidade que eu trabalho, então é conhecer mesmo isso, a realidade do território de onde você tá trabalhando, de quem tá participando do grupo né, gosto, cultura deles para você poder fazer o planejamento do grupo, sobre o que você vai falar, o que você vai orientar né" (E23; enfermeira).

Adicionalmente, nesta categoria são indicados outros espaços da APS para trabalhar a problemática da alimentação (Figura 1). Além dos grupos, o enfrentamento das questões alimentares pode ser feito por meio de outras ações com o apoio da rede de agentes da APS: os profissionais de saúde juntamente com os usuários do SUS na APS. Porém, se identifica que este é um problema específico de alguns sujeitos, não uma questão que atinge coletivamente as pessoas do território:

"Eu acho que tem que trabalhar com a realidade da família. Isso é mais fácil não em grupo, em visita. Aí no caso eu... daria um atendimento mais personalizado. Na hora, no momento eu tentaria ver o caso daquela pessoa, que você me disse. É mais focado só nele, tentaria achar uma solução junto com ele, com a família, com a equipe, agente comunitário, auxiliar de enfermagem. Seria uma coisa mais personalizada. Eu faria isso no momento" (E3; enfermeira).

Dentre as estratégias para a alimentação e nutrição, estão as ações coletivas, que se destacam por serem espaços locais potentes, nos quais as pessoas encontram as redes sociais que se conformam no território e podem impulsionar algum avanço nessas ações, bem como fomentar sua sustentabilidade no tempo. Entretanto, trata-se de espaços desafiantes de serem construídos quando considerada a lógica dos serviços de saúde, em que persiste a produção quantitativa de consultas e de procedimentos individuais, além das dificuldades reais, por demandarem tempo de preparo e organização para a ação.

Ressaltamos ainda que, visando à efetivação do DHAA na APS em meio à diversidade de formas de atuação profissional e de proposições de ações, a educação alimentar e nutricional precisa ser construída como estratégia teórico-metodológica de conhecimento e de prática para a atuação problematizadora. O "trabalhar junto" pode ser uma iniciativa para a implementação de ações educativas "problematizadoras e ativas que favoreçam o diálogo na direção da construção de práticas alimentares autônomas e voluntárias" 17 (p. 23). 
Deve-se buscar, junto à população, a construção de interações e significados que compõem o comportamento alimentar e as questões ligadas aos sistemas alimentares. A educação alimentar e nutricional é uma estratégia importante para organização e atuação coletiva no cenário da APS, voltada para ações de saúde e de alimentação e nutrição enquanto direitos sociais. Os profissionais de saúde representam um grupo fundamental para a contraposição política à lógica "alimento-mercadoria-doença", tomando como atuação militante o seu trabalho cotidiano e suas ações no serviço. Por sua natureza política e forma de intervenção no mundo, necessária para o pensamento e reflexão dos interesses humanos, a APS pode se constituir como um espaço pedagógico privilegiado para a construção de comunicação dialógica (escuta, fala, silêncio), de motivação e exposição de desafios, de curiosidade, da compreensão e ação coletiva de algo comum para o enfrentamento e ampliação da capacidade de respostas dos serviços de APS para os problemas de saúde dos usuários.

\section{Conclusão}

Concluímos haver três diferentes formas de atuação profissional em relação à problemática da alimentação na APS, porém ancoradas em noções de alimentação muito similares: aprisionadas pelas desigualdades sociais numa perspectiva insolucionável, a transformação da realidade social parece impossível.

A diferenciação de classes (sociais e econômicas) está pronunciadamente subsidiando as práticas na APS do município estudado quando os profissionais abordam as questões alimentares. Adicionalmente, a atuação dos profissionais da APS tem graus diferentes de responsabilização com a construção de ações que promovam a efetivação do DHAA. No entanto, em nenhum ponto deste espectro se atinge o pleno reconhecimento e responsabilização com este direito. Mesmo quando se parte do trabalho em equipe e da relação interpessoal baseada na realidade do usuário, a não concretização do DHAA é removida da esfera coletiva e passa a ser olhada como um problema específico de um ou outro usuário. Quando o foco está no acesso e disponibilidade de alimentos, dimensões importantes da segurança alimentar e nutricional, recorre-se majoritariamente à figura do especialista, desconstruindo a noção de articulação dos diferentes saberes na concretização da saúde. Por último, há ainda a perspectiva mais simplista, e consequentemente mais insuficiente para responder o problema posto, que se sustenta nos conhecimentos biomédicos para tratar questões sociais da dimensão do mundo da vida, não restritas à esfera morfofuncional do corpo.

Este estudo permitiu aproximações entre "o que fazer e como atuar" a partir das formas de apropriação da alimentação por meio das concepções, da atuação profissional e das propostas de ações para a efetivação do DHAA na APS. Em adicional, possibilitou elucidar a necessidade de compreensão dos direitos sociais na formação e na prática profissional da área da saúde e do fortalecimento da responsabilidade ética, social e política dos profissionais da saúde na APS. A realidade concreta e as experiências nas UBSs, com maior prevalência para a população periférica, foram o locus de constituição das fontes de informação e orientação para os profissionais; e isso serviu de subsídio para a abordagem e atuação nas ações em alimentação e nutrição.

Dentre os caminhos possíveis para o debate e a transformação do que foi explicitado neste estudo, está a formação profissional da área da saúde que precisa estar orientada e direcionada para atuação coerente com o enfrentamento das questões sociais que aniquilam a população, a prática profissional que requer consciência política para compreensão das necessidades de saúde da população e, por fim, ações coletivas que mobilizem tanto profissionais quanto população para sua emancipação humana. 


\section{Colaboradores}

L. D. S. Guerra contribuiu com a concepção do estudo, coleta dos dados, transcrição do material, análise dos dados, redação e revisão do manuscrito. F. C. Botelho contribuiu com a coleta dos dados, transcrição do material, análise dos dados, redação e revisão do manuscrito. A. M. Cervato-Mancuso contribuiu com a concepção do estudo, redação e revisão do manuscrito.

\section{Informações adicionais}

ORCID: Lúcia Dias da Silva Guerra (0000-00030093-2687); Fernanda Cangussu Botelho (00000003-1103-9181); Ana Maria Cervato-Mancuso (0000-0002-9276-8943).

\section{Agradecimentos}

À Fundação de Amparo à Pesquisa do Estado de São Paulo (FAPESP) pelo financiamento da pesquisa (processo no 2012/02264-2). Ao Programa de Pós-graduação em Nutrição em Saúde Pública da Faculdade de Saúde Pública da Universidade de São Paulo. À Secretaria Municipal de Saúde de São Paulo e aos profissionais da atenção primária à saúde.

\section{Referências}

1. Silva HF, França Junior I. A combinação de projetos políticos distintos na atenção básica à saúde: impactos político-sociais e a desconstrução do SUS. Saúde Soc 2016; 25:423-42.

2. Rigon SA, Schmidt ST, Bógus CM. Desafios da nutrição no Sistema Único de Saúde para construção da interface entre a saúde e a segurança alimentar e nutricional. Cad Saúde Pública 2016; 32:e00164514.

3. Alves KPS, Jaime PC. A Política Nacional de Alimentação e Nutrição e seu diálogo com a Política Nacional de Segurança Alimentar e Nutricional. Ciênc Saúde Colet 2014; 19:433140.

4. Giovanella L, Mendonça MHM. Atenção primária à saúde. In: Giovanella L, Escorel S, Lobato LVC, Noronha JC, Carvalho AI, organizadores. Políticas e sistema de saúde no Brasil. Rio de Janeiro: Editora Fiocruz; 2012. p. 575625.

5. Organização Pan-Americana da Saúde. Sistemas de saúde com base na atenção primária: estratégias para o desenvolvimento de equipes de atenção primária em saúde. Washington DC: Organização Pan-Americana da Saúde; 2009. (Série Renovação da Atenção Primária em Saúde nas Américas, 1).

6. Mendes A, Carnut L, Guerra LDS. Reflexões acerca do financiamento federal da atenção básica no Sistema Único de Saúde. Saúde Debate 2019; 42:224-43.

7. Ray S, Ball L, Laur C. Nutrition education for public health. Public Health 2016; 40:3-6.

8. Boog MCF. Doação de alimentos como ação emergencial de combate à fome - subsídios aos COMSEAS. Segurança Alimentar e Nutricional 2006; 13:78-84.

9. Silva KC, Delduque MC. Acesso a fórmulas nutricionais no Sistema Único de Saúde: um olhar do sistema de justiça. Rev Direito Sanit 2019; 20:155-76.

10. Aliaga MA, Santos SMC, Trad LAB. Segurança alimentar e nutricional: significados construídos por líderes comunitários e moradores de um bairro popular de Salvador, Bahia, Brasil. Cad Saúde Pública 2020; 36:e00169218.

11. Botelho FC, França Junior I. Como a atenção primária à saúde pode fortalecer a alimentação adequada enquanto direito na América Latina? Rev Panam Salud Pública 2018; 42:e159.

12. Cervato-Mancuso AM, Tonacio LV, da Silva ER, Vieira VL. A atuação do nutricionista na atenção básica à saúde em um grande centro urbano. Ciênc Saúde Colet 2012; 17:3289-300.

13. Jaime PC, Delmuè DCC, Campello T, Oliveira e Silva D, Santos LMP. Um olhar sobre a agenda de alimentação e nutrição nos trinta anos do Sistema Único de Saúde. Ciênc Saúde Colet 2018; 23:1829-36. 
14. Vincha KRR, Vieira VL, Guerra LDS, Botelho FC, Pava-Cárdenas A, Cervato-Mancuso AM. "Então não tenho como dimensionar": um retrato de grupos educativos em saúde na cidade de São Paulo, Brasil. Cad Saúde Pública 2017; 33:e00037116.

15. Botelho FC, Guerra LDS, Pava-Cárdenas A, Cervato-Mancuso AM. Estratégias pedagógicas em grupos com o tema alimentação e nutrição: os bastidores do processo de escolha. Ciênc Saúde Colet 2016; 21:1889-98.

16. Cervato-Mancuso AM, Vincha KRR, Santiago DA. Educação alimentar e nutricional como prática de intervenção: reflexão e possibilidades de fortalecimento. Physis (Rio J.) 2016; 26:225-49.

17. Secretaria Nacional de Segurança Alimentar e Nutricional, Ministério do Desenvolvimento Social e Combate à Fome. Marco de referência de educação alimentar e nutricional para as políticas públicas. Brasília: Ministério do Desenvolvimento Social e Combate à Fome; 2012.

18. Guerra IC. Pesquisa qualitativa e análise de conteúdo: sentidos e formas de uso. Estoril: Principia; 2006.

19. Bauer MW, Gaskell G. Pesquisa qualitativa com texto, imagem e som: um manual prático. Petrópolis: Editora Vozes; 2002.

20. Comitê de Direitos Econômicos, Sociais e Culturais do Alto Comissariado de Direitos Humanos, Organização das Nações Unidas. Comentário geral no 12: o direito humano à alimentação. Nova York: Organização das Nações Unidas; 1999.

21. Organização das Nações Unidas para a Alimentação e a Agricultura. Diretrizes voluntárias em apoio à realização progressiva do direito à alimentação adequada no contexto da segurança alimentar e nutricional. Roma: Organização das Nações Unidas para a Alimentação e a Agricultura; 2015.

22. Brasil. Lei no 11.346 , de 15 de setembro de 2006. Cria o Sistema Nacional de Segurança Alimentar e Nutricional - SISAN com vistas em assegurar o direito humano à alimentação adequada e dá outras providências. Diário Oficial da União 2006; 18 set.

23. Brasil. Emenda Constitucional no 64, de 4 de fevereiro de 2010. Altera o art. 6o da Constituição Federal, para introduzir a alimentação como direito social. Diário Oficial da União 2010; 4 fev.

24. Vasconcelos FAG, Machado ML, Medeiros MAT, Neves JA, Recine E, Pasquim EM. Public policies of food and nutrition in Brazil: from Lula to Temer. Rev Nutr 2019; 32:e180161.

25. Alston P. The populist challenge to human rights. J Hum Rights Pract 2017; 9:1-15.

26. Boschetti I. Expropriação de direitos e reprodução da força de trabalho. In: Boschetti I, organizadora. Expropriação e direitos no capitalismo. São Paulo: Cortez Editora; 2018. p. 131-65.
27. Bosi MLM. A face oculta da nutrição: ciência e ideologia. Rio de Janeiro: Espaço e Tempo/ Editora UFRJ; 1988.

28. Castro J. Geografia da fome. Rio de Janeiro: Civilização Brasileira; 2008.

29. Carnut L. Para uma crítica ao pós-moderno: o social nas ciências da saúde e o papel da educação crítica - primeiras reflexões. Práxis Comunal 2019; 2:152-67.

30. Guerra LDS, Cervato-Mancuso AM, Bezerra ACD. Alimentação: um direito humano em disputa - focos temáticos para compreensão e atuação em segurança alimentar e nutricional. Ciênc Saúde Colet 2019; 24:3369-94.

31. Guedes CR, Nogueira MI, Camargo Jr. KR. A subjetividade como anomalia: contribuições epistemológicas para a crítica do modelo biomédico. Ciênc Saúde Colet 2006; 11:1093-103.

32. Leão MM, Castro IRR. Políticas públicas de alimentação e nutrição In: Kac G, Sichieri R, Gigante DP, organizadores. Epidemiologia nutricional. Rio de Janeiro: Editora Fiocruz/ Atheneu; 2007. p. 519-41.

33. Burlandy L. A atuação da sociedade civil na construção do campo da alimentação e nutrição no Brasil: elementos para reflexão. Ciênc Saúde Colet 2011; 16:63-72.

34. Ribeiro H, Jaime PC, Ventura D. Alimentação e sustentabilidade. Estud Av 2017; 31:185-98.

35. Maluf RS, Reis MC. Conceitos e princípios de segurança alimentar e nutricional. In: Rocha C, Burlandy L, Magalhães R, organizadores. Segurança alimentar e nutricional: perspectivas, aprendizados e desafios para as políticas públicas. Rio de Janeiro: Editora Fiocruz; 2013. p. 15-42.

36. Pinstrup-Andersen P. Food security: definition and measurement. Food Secur 2009; 1:5-7.

37. Magalhães R. Regulação de alimentos no Brasil. Rev Direito Sanit 2017; 17:113-33.

38. Pierantoni CR. As reformas do Estado, da saúde e recursos humanos: limites e possibilidades. Ciênc Saúde Colet 2001; 6:341-60.

39. Cunha GT, Campos GWS. Apoio matricial e atenção primária em saúde. Saúde Soc 2011; 20:961-70

40. Slomp Junior H, Feuerwerker LCM, Merhy EE. Histórias de vida, homeopatia e educação permanente: construindo o cuidado compartilhado. Ciênc Saúde Colet 2015; 20:1795-803.

41. Langdon EJ. Os diálogos da antropologia com a saúde: contribuições para as políticas públicas. Ciênc Saúde Colet 2014; 19:1019-29.

42. O'Hare BAM, Devakumar D, Allen S. Using international human rights law to improve child health in low-income countries: a framework for healthcare professionals. BMC Int Health Hum Rights 2016; 16:11. 


\section{Abstract}

This study aimed to understand the forms of professional work and proposed actions to achieve the human right to adequate food (HRAF) in the context of primary healthcare (PHC). Using a qualitative approach, the authors conducted semistructured interviews (from May 2013 to July 2014) with healthcare workers that conducted educational groups on food and nutrition in PHC in the city of São Paulo, Brazil. Content analysis was performed to identify the proposed actions on food, with HRAF as the theoretical basis. We identified three categories of professional work based on the proposed actions for food and nutrition. The first approaches food as a biomedical dimension. The second focuses on access and availability of foods in the territory. The third approaches users' local food reality, centered on the team's work. The proposed actions feature those conducted by individuals with obligations towards HRAF (healthcare workers in PHC) and those performed by rightsholder (users of PHC in the Brazilian Unified National Health System). Food in contexts of poverty is treated as a problem with no solution. This study allowed approximations between "what to do" and "how to act" based on ways of grasping food through the definitions, professional work, and proposed actions to achieve HRAF in PHC. It also allowed elucidating the need to understand food as a human right and strengthening the responsibility of healthcare workers in PHC as duty-bearers towards HRAF in the context of social policies.

Primary Health Care; Human Rights; Food and Nutrition Security; Unified Health System

\section{Resumen}

Este estudio tuvo el objetivo de comprender las formas de actuación profesional y las propuestas de acciones para hacer efectivo el derecho humano a una alimentación adecuada (DHAA), en el contexto de la atención primaria a la salud (APS). A partir del abordaje cualitativo, llevamos a cabo entrevistas semiestructuradas (durante el período de mayo de 2013 a julio de 2014) con profesionales de salud que desarrollan grupos educativos sobre alimentación y nutrición en la APS de la ciudad de São Paulo, Brasil. Realizamos un análisis de contenido buscando identificar las acciones propuestas en un entorno de la alimentación y tomando como base teórica el DHAA. Identificamos tres categorías de actuación profesional a partir de las propuestas de acciones en alimentación y nutrición. La primera tiene la alimentación como dimensión biomédica. La segunda está enfocada en el acceso y disponibilidad de alimentos en el territorio. La tercera tiene la realidad alimentaria local, de los usuarios, centrada en la actuación del equipo. Entre las propuestas de acciones habia unas para que fueran realizadas por los portadores de obligaciones de los DHAA (profesionales de la APS) y otras para que los propios titulares del derecho las ejecutaran (usuarios de la APS en el Sistema Único de Salud). La alimentación en contextos de pobreza se trata como un problema sin solución. Este estudio permitió aproximaciones entre "qué hacer" y "cómo actuar", a partir de las formas de apropiación de la alimentación mediante concepciones, de la actuación profesional y de las propuestas de acciones para la efectivación del DHAA en la APS. Asimismo, posibilitó elucidar la necesidad de comprensión de la alimentación como un derecho humano y el fortalecimiento de la responsabilidad de los profesionales de la APS, como agentes portadores de obligaciones del DHAA, en el contexto de las políticas sociales.

Atención Primaria de Salud; Derechos Humanos; Seguridad Alimentaria y Nutricional; Sistema Único de Salud
Recebido em 13/Ago/2020

Versão final reapresentada em 30/Out/2020

Aprovado em 29/Dez/2020 